\title{
SELF-DIRECTED LATER LIFE LEARNING: INDIVIDUAL AND SOCIAL CONTEXTS
}

\author{
ŠATIENĖ Salomėja \\ Klaipèda State University of Applied Sciences, Klaipèda, Lithuania
}

\begin{abstract}
The purpose of the study was to investigate how self-directed later life learning is utilized and interpreted by older adults in their particular environments. The following questions were raised: What are the opportunities for older adults' engagement in self-directed learning in their environments? How older adults realize their self-directed learning in response to the opportunities provided by their environments? Thematic analysis was used as research method to analyse participants' experiences and meanings they attribute to self-directed learning in their actual environments. The data was collected through semistructured interviews with 12 older adults engaged in their self-directed learning pursuits. The findings from the study showed that older adults' engagement in generativity-based activities, interest-based activities and social networks are contexts of self-directed learning in later life; these contexts support older adults' selfdirected learning by providing learning impetus, opportunities and resources; realization of self-directed learning is influenced by ageing-related changes and individual circumstances of older adults.
\end{abstract}

Keywords: Individual context; Later life learning; Self-directed learning; Social context.

\section{Background}

Some recent research in the field of older adult learning has shown that learning possibilities and learning readiness in later life are affected by a range of contextual factors including the social environment (Withnall, 2006; Hodkinson et. al., 2008), material resources for informal learning (Schmidt-Hertha, 2013) or individual attitudes to learning abilities (Friebe \& Schmidt-Hertha, 2012; Tam \& Chui, 2016; Withnall, 2006). The need for exploring development of older adult learning in relationship with specific contexts has been emphasized in later life learning scholarship. Merriam et al. (2007) pointed out the importance to understand the extent to which context contributes to autonomy in self-directed learning. It has also been recognized, that learning 
patterns may differ with respect to different social and cultural settings (Boulton-Lewis et al., 2016; Merriam \& Bierema, 2014; Hiemstra \& Brockett, 2012; Findsen \& Formosa, 2011). The exploration of contextual aspects in the present study is important due to the fact that in Lithuania there has been limited research on influences of specific learning contexts on learning in later life from the older learner perspective.

In the present study we will explore older adults' perceptions of their self-directed learning contexts. The following questions are raised: What are the opportunities for older adults' engagement in self-directed learning in their environments? How older adults realize their selfdirected learning in response to the opportunities provided by their environments? With the main aim of the present study to further the understanding of the influence of context in older adults' selfdirected learning, we set the following objectives: (a) to identify the environments in which older adults utilize their self-directed learning; (b) to explore the influence of the social context for realization of self-directed learning in later life; (c) to identify the individual circumstances influencing self-directed later life learning..

\section{Theoretical framework}

Self-directed learning as a modern learning paradigm has been subject to broad interpretation (Owen, 2002). In this study we approach the concept of self-directed learning as autodidactic self-learning, i.e. the individual non-institutional pursuit of learning opportunities (Candy, 1991). In this view self-directed learning is defined as a form of informal learning, which is both intentional and conscious (Schugurensky, 2000). In the context of later life learning, selfdirected learning is "a continuum of learning from individual personal efforts to a lifestyle of learning“ (Roberson, 2004, p. 214). The recent researches on later life learning show that education and continued learning are rated highly by senior learners and are associated with mental health and improvement of intellectual abilities (Boulton-Lewis et al., 2006; Tam, 2013), self-fulfilment, and self-enrichment (Tam, 2013), or adjusting to ageing (Roberson, 2005). Learning in later life may be viewed as becoming (Hodkinson et. al, 2008), when the learners undergo a process of personal construction and reconstruction adapting to the new age-related circumstances. The learner's commitment to learning and sense of personal competence as a learner (Merriam \& Caffarella,1999), life experience, motivation, previous education, self-concept (Hiemstra \& Brocket, 2012), learning strategies, the ability to reflect on and evaluate one's own learning 
(Schmidt-Hertha, 2013) have been shown to play an important role in self-direction in later life learning. From the constructivist perspective, self-directed learning may be viewed as "a process of constructivist understanding and development towards a more holistic being within a lifespan perspective" (Kasworm, 2011, p. 24).

The focus of this study on the context in later life learning is predicated on a view that older people are not a homogeneous group (Glendenning, 1992). The older individual is affected by continually changing social and cultural context with its inherent situational and personal factors (Withnall, 2006). The social context influences both the learner and the learning process (Hiemstra, Brockett, 2012) and contributes to autonomy in self-directed learning (Merriam et.al., 2007). As pointed out by Hiemstra and Brockett (2012), the focus on the individual learner without considering the impact of the context in which such learning takes place has been one of the most contested aspects of self-directed learning over the years and there has been "relatively little work at the intersection of the learner and context elements" (p. 159). Viewing learning in later life from a constructivist perspective (Tusting \& Barton, 2006), the meaning of learning to the aging individual is emphasized and linked to their lives and self in specific social and cultural contexts. Thus the older adults' lifestyle and environment become significant to learning. Constructing knowledge from their daily life, older adults develop specific learning patterns, which may be affected by the individual's learning space (Jarvis, 2012), and the challenges arising from the social environment if combined with the availability of personal and external learning resources (SchmidtHertha, 2013).

\section{Methodology}

\section{Approach}

The social constructivist perspective (Berger \& Luckmann, 1999) was adopted in the present study, viewing reality as socially constructed. The qualitative research paradigm was adopted to explore the lived experiences of the older adults engaging in their self-directed learning. As pointed by Candy (1991), in terms of research into self-directed learning, "examining the attitudes and intentions of learners is essential to gaining full understanding of their actions" ( $p$. 438). Based on the premise of the interaction between the participant and context, the study looks into learners' perceptions of their self-directed learning environments, which is essential for better understanding of the participants' ${ }^{6}$ realities and the meanings they associate with these realities. 


\section{Participants}

The purposeful sampling approach was employed to find information-rich participants for the study. The strategies of participant recruitment included the snowball technique and convenience. The criteria included post-retirement age and evidence of engagement in self-directed learning pursuits. There were 12 participants including 10 women and 2 men aged 64 to 82, living in a rural area, with the retirement period ranging from 6 months to 15 years. The educational level ranged from upper-secondary to higher education. The occupational backgrounds included eight participants with a teaching profession, one participant with a medical background, two retired accountants, and a retired administrative professional.

\section{Data collection}

The semi-structured interview was employed as a method to collect the empirical data. The interview was applied to elicit accounts of typical situations and their meanings to participants (Kvale \& Brinkmann, 2009). There were 12 personal interviews conducted with the participants in November, 2016 and April, 2017. Each interview lasted from 40 to 80 minutes. A small sample of open-ended interviews was selected to "add depth, detail, and meaning at a very personal level of experience" (Patton, 1990, p. 18). The participants were asked to describe their needs for learning, and activities in which they acquired the knowledge and skills necessary for maintaining their life in their living environments. The interview questions were formulated around the following: How does your everyday life require to gain knowledge or skills? How do you acquire the knowledge/skills you need? What activities do you engage in which demand new knowledge or skills? Can you describe a recent activity that you learned a lot? Tell me about your interests and hobbies. What opportunities for learning do you see in your environment? To ensure the researcher competence, the interview protocol was tested through a pilot study, and some changes were made to the interview procedure. The interviews were audio-recorded, transcribed verbatim by the researcher and validated against original records. The transcripts were approved by the participants to ensure the correctness of representation.

\section{Data analysis}

Thematic analysis was used as an empirical research method which focuses on participants' experiences and the meanings they attribute to the research issue in their actual 
environments (Braun \& Clarke, 2014). Thematic analysis allows the researcher to uncover the characteristics of the research phenomenon and provide in-depth explanations, to identify typical patterns and to formulate the themes related to the research problem. Validity in terms of interpretive adequacy may be ensured as correspondence of researcher and participant constructs (Patton, 1990). The inductive thematic analysis was carried out following the stages of thematic analysis (Braun \& Clarke, 2006), which included reading and re-reading the transcripts, manual coding, searching for themes, reviewing themes, defining and naming themes and writing up the report. The data analysis started with the first interview, which allowed for a more informed approach to be adopted in the following interviews, the researcher adding focus on particular aspects and asking more relevant questions. Further reading and rereading the transcripts in an iterative process was carried out to identify emerging categories, considering how they could form clusters, and developing primary themes. Final interpretation of the data was carried out after achieving data saturation when the interviews were completed. The semantic themes were derived which comprised explicitly expressed meanings in the participants' discourses.

\section{The issues of validity and reliability}

The trustworthiness (Lincoln \& Guba, 1985) of the research study was ensured by following a series of procedures establishing credibility, transferability, dependability and confirmability of the findings. The credibility of the data was ensured by purposeful sampling, member check, referential adequacy and a reviewer validation operation (Cummins, 2010). A reviewer performed an independent coding of data, and discussed the categories and themes with the researcher. The transferability of the study was ensured by accurate comprehensive descriptions. The maintenance of files, including audio records of interviews, transcripts, and the researcher's field notes, was performed to ensure dependability and confirmability (Lincoln \& Guba, 1985).

\section{Research ethics}

The research was carried out in compliance with the principles of research ethics and respect to the participants' rights (Howe \& Moses, 1999): the research participants were informed about the purpose of the research and the methods of data collection; the participants volunteered to the research; the written consent was obtained from the participants; the privacy of the participants 
was respected by avoiding very personal questions; the confidentiality of the participants' data was ensured.

\section{Findings}

Four themes were identified that illustrate older adults' engagement in self-directed learning in their particular environments: (1) Older adults engage in self-directed learning in generativity-based contexts; (2) Older adults engage in self-directed learning in interest-based contexts; (3) Older adults utilize self-directed learning in social networks; (4) Older adults adapt their learning to ageing-related and individual circumstances. My argument is that the themes identified through analysis provide important aspects showing that self-directed learning of older adults is strongly connected with the environments in which the learning occurs and is affected by individual circumstances. To support my interpretation of the themes, I will provide a number of examples from the participants discourses.

\section{Older adults engage in self-directed learning in generativity-based contexts}

The generativity perspective applied to later life learning looks at development of competences enabling older people to contribute to the social contexts in which they participate (Villar, 2012). The empiric data of the present study shows that generativity is a key issue in older adults' beliefs and experiences of self-directed learning.

"What will I leave behind?" The participants explicitly spoke about feeling an urgent need for contributing to their environment. For some older people it means Erikson's (1963) generativity as one's legacy: "I somehow think it's in my nature... as it's about time for me to start thinking of leaving this world as my health has deteriorated... so I have started asking myself "What do I have and what will I leave behind?" There is a variety of generative activities that older adults engage into ranging from family-related tasks to voluntary community-level activities. The community-level contributions reported by the participants included volunteering for the local museum, collecting materials for a book about the village, setting up a prayer group, writing articles to the local newspapers, or participating in the sub-district council. The complexity of these activities requires relevant competences which an older person may not have developed yet, but feels motivated to learn "following my own understanding and insight". For example, Mrs. A spoke about her commitment to maintenance of her cottage inherited from her parents, which was a local 
landmark of ethnic architecture: „There are some people coming to see it, so we need to keep its authenticity“. Some of the activities may be large-scale projects and require co-operation and collaboration with other people like in Mrs. B's example, who involved some retired teachers in the research job of interviewing the local residents and collecting materials for the school history. However, the engagement in community-oriented activities for some older people needs encouragement from other community members ("I can write an article if somebody asks and I do when they need one, but otherwise - no') or some people may be more withdrawn ("I do admire those people with initiative, who inspire and enlighten others, but I don't see myself in that role. May be I am of a less sociable disposition").

"I must make commitments to my family". There are some areas of activity typically related to the roles of a grandparent or an elderly person in an extended family: looking after grandchildren, helping grandchildren or younger relatives with their learning at school, looking after elderly or sick family members, or creating a family history as legacy to one's family. However, those tasks may be really challenging and demanding for older adults in terms of competences necessary for their performance, for example, taking care of grandchildren may require development of a new understanding ("they have a different approach to child up-bringing, and I have to prove my point") or skills ("I create my own fairy tales to tell my grandchildren"). "Full-time nursing" of sick family members is generally viewed as both emotionally and physically challenging experience. However, it may also be an impetus for seeking the knowledge which informs the practice of caring and development of one's coping abilities: "Now I have so much knowledge that I can give advice to other people nursing their family members".

"It did not stop with my retirement" Continuing involvement in generative preretirement activities is a common strategy of older adults seeking productivity in their social environments: "The museum has been my love for 20 years now. It did not stop with my retirement, and all my current activities are linked with it. That's something I haven't finished when working". The continuity of activity allows the older people to further develop their skills and build new knowledge on the prior knowledge, e.g. Mrs. B prepared materials for the museum website, wrote and edited the texts using her skills as a linguist. But she also admitted that her voluntary activity in the local museum required learning new skills: how to compile, systemize and analyze the data, how to take good quality photographs, how to use computer programmes for formatting the 
materials and photographs, etc. Learning for engagement in a new area of activity is another strategy employed by older people in their pursuit of generativity. Older people can engage in learning when considering possibilities for a new paid job, like Mrs. H, a retired teacher of English, said: „I did a computer literacy course when I had an opportunity, as I thought I could try and find a translation job online. Mr. E started a small poultry farm which required knowledge of raising domestic birds. An older person may be projecting future trajectories of their lives with an element of contribution to the social environment: „I have developed a future plan for myself: when I completely retire, I will invite like-minded people to my home for discussions of books, films, or even lecturers. I would not like to withdraw and feel not needed“. The learning strategies developed by the participants generally depended on the type of activity and the resources available in their environments: "I look for information on the Internet, for example, how to organize a reunion - I read about other people“s experience, and I adopt some ideas“, ,,we went to watch another prayer group, however, we did not adopt their mode, but developed our own way". The competence needed for looking after a sick person may be gained through experience: "I just learnt being with him - you know you cannot burden other people with your problems", "I tried to understand things myself - learnt to be a nurse and a psychologist, and that learning was natural".

\section{Older adults engage in learning in interest-based contexts}

„I am myself - I am still interested in the same things like before [retirement]. " The continuity in maintaining pre-retirement interests was a dominant theme in the participants' reports: "I have always had an interest in psychological and philosophical literature", "I did not feel any transition or a new phase in my interests". However, the scope and the intensity of involvement in the interests-based activity may have reduced. Reading literature was identified as a common "lifelong" interest, and most of the participants reported having rich collections in their private libraries. There are various purposes to engaging in this activity: „a desire to know more“, "to refresh my thoughts", "keep up with the new literary developments", "for relaxation". Older adults may use reading as a learning strategy for coping with emotional problems: "getting insight into loneliness, and many things“, ,some light read about other people's lives so that you don't need to look into your own life“, „I started looking for ways to cope with my condition, and I found a book which helped; I still read that book to find answers to my emotional problems“. For older adults reading activity can be used as a source of knowledge in a specific area. The reading patterns of 
some older adults can manifest a „lifestyle of learning“. For example, Mrs F spoke about her continued engagement in reading as a serious learning activity: „I read a book or more a week, especially in autum and winter, which makes up about 50 books a year. I make records of the books I read including a short summary, some notes about the things I liked, or my opinion. For future reference or the children may read some exerpts some day“.

„I do things that are challenging - it's interesting to me“. Some of interest-related activities have explicit self-directed learning elements like setting a goal to learn a new skill (knitting, embroidery, learning a language, creating a Facebook profile, wood or metal work, photography), openness to new experience through "trying new things in handicraft or cooking", "experimenting with plants and flowers", or challenging oneself mentally ("When knitting, I try new patterns and intricate models of garments to keep my brain working"). . Gardening, which is a common activity in rural older adults' lives, is acknowledged as a learning environment offering space for creativity ("a beautiful garden is the result of the vision you make"), or knowledge and skill development (,you need understanding and effort“, "it's not a problem to gain knowledge of gardening, acquisition of skills is more difficult").

„I never consciously set a goal for improving myself - I just follow my heart“. Older adults may not set themselves specific goals for learning, and just „listen to one“s inner guidance“ and „do the things which they feel like doing“ when engaging in the activities in their interestrelated contexts. Some leisure activities may provide a natural environment for learning and an older person develops a learning pattern within it: „Lately I have found a new source for knowledge and spiritual development - a radio station where I can listen to lectures on a range of topics, book reviews, excerpts from new literary works, talks on psychological issues and music. Now I wake up and go asleep with this radio station, which has become part of life in my old age“. Learning is implicit in most of the activities related to maintaining one's interest in ,new developments in politics and everything“, a need to know „what is going on in the world and in Lithuania“, watching „documentaries about other countries, about towns in Lithuania“, growing flowers (,,initially I had an idea of creating a traditional Lithuanian flower garden, and now the number of flowers has reached 68 kinds") or "going and seeing what I haven't seen yet". Travelling, which is generally considered a useful leisure activity in later life (Lamdin, 1997; Roberson, 2002), may also be associated with rich learning experiences. It was taken advantage of in a variety of ways including development of multicultural insights (,when I was travelling abroad, I always wanted to 
understand the local life"), opportunity to expand the knowledge of the national culture and heritage („I keep making notes.. about different places in Lithuania $<>$ every summer my son takes me to an interesting place, so I always read about it before"), or receiving some additional benefits from social interaction when travelling ("In our prayer group we started singing the carols which I had learnt during my pilgrimage tours"').

„Here one can find opportunities, if you are really interested in finding them." Interest-related learning in many ways was associated with resources available in the community environments, which were not overtly learning environments: facilities and events, including lectures, presentations of books at the library, and various educational activities. Most participants admitted that they were selective about activities and only went to those events which they expected to be worthwhile for them. The stimulating factors included meeting the individual interests („I go to the library events to „hear the spoken word live“), openness to new experiences (,one can learn a lot of new things“), opportunities for socializing (,it makes you feel part of the community“), taking advantage of free and accessible opportunities („I would not miss any opportunities provided here, first of all because it's so close, you don't need to waste time on the journey“"), personal attention (,the librarian knows what I need and lets me know when there is a copy available”), or involvement of other family members (,,we go there with all the family - my daughters and grandchildren“). The discouraging factors include having no interest in what is offered („I am not keen on those educational activities, as I can do all those things myself"), having a detached disposition („I don't see myself taking part in some noisy events“) or disbelief in one“s abilities (,you should have some understanding or abilities about those things"). However, the older adult may perceive some limitation in the environment for their learning pursuits: „I would like to do a course in the English language, but it is probably not feasible to organize it here, as hardly anybody would attend it".

\section{Older adults utilize self-directed learning in social networks}

„I believe that a person at my age should never be alone“. Retirement brings changes in the individuals' social environment (,,as you used to be surrounded by people all day, you feel the difference now). Older people recognize the increased importance of social connections in postretirement for emotional comfort (,you need somebody to talk to and to be listened by“) and personal development (, I have a friend who is ,,a driving force“ for me“). Having well-established 
social connections provides secure and stimulating social environment for personal growth in later life („If you have somebody at your side to support you, somebody who raises you up or pulls you out.. otherwise it's difficult when you have to cope alone with all your responsibilities"), whereas detachment may result in decreased levels of activity (,we would discuss political issues with my husband a lot, but now there is nobody to discuss with“), or disengagement (,when you are alone, there are moments when you get so depressed that you lose interest in anything").

"I ask my knowledgeable friends". Social networks become a resource for gaining knowledge or skills: older adults may rely on knowledgeable people in their immediate social environments including family (,we all learn through communication with children, and grandchildren“), friends („I ask my friends, who have the equipment and skills“), neighbours (“I ask my neighbours for advice .... there is a retired teacher of biology“"), or community professionals (,our GP is a „non- traditional“ doctor - she cares about our physical and spiritual health, so you always get advice and literature to read when you see her"). Learning through relations with their family members may entail a number of patterns: providing assistance with finding sources of information, involvement in discussions on a variety of topics, sharing ideas, or receiving informed advice. Learning through social interaction may be preferred to getting knowledge through other modes: „You may read something, but it‘s not the same - you need practical, specialist advice“, „this is a more simple way of learning those things“, „I tried to ask some advice from a woman who had recovered from a similar disease“. Social interaction serves as an incentive to learning when older people are directly encouraged to learning and supported by people in their immediate environment („My son encourages me to read books about spiritual growth and focus more on spiritual life instead of my everyday activities“), or the learning activity may be triggered by specific family circumstances ("I learnt to use Skype to keep in touch with my daughter when she was on a traineeship in Japan“, „my son has an English speaking girlfriend - now I will have to brush my English“).

\section{„You get out of the circle of your personal problems and feel yourself part of society“.}

There is a connection between an older person's engagement in learning and establishing oneself in the social environment and maintaining one's status. As retirement may be associated with loss of the individual's previous status in community (,,when you retire, you feel not lonely, but alone as a contrast to being part of a community workwise"), the older adults pursue personal development through learning in order to maintain their status in their social environment (,,it makes you feel you 
are not „thrown overboard“). Participation in learning may also be stimulated by a need for socializing: „Very often it's the boredom and loneliness that make people go somewhere and participate“. The participants in our study argued that older people must be pro-active to establish themselves in their social contexts: „You must do it yourself - go and participate, show your initiative - you will have as much as you create yourself". The social networks may be linked to pre-retirement relationships: „The group of people I communicate and socialize with consists of other retired teachers like me, with whom I worked from the beginning of my career till retirement. Most of them are my ex-colleagues and also friends. They are of the same age and background, and we have a lot in common. We support each other and share our leisure“. The learning environment embedded in social interaction within the social network includes discussion of books, sharing books, attending community cultural events, consulting each other on some everyday life problems or gaining practical knowledge in gardening, handicraft, or cooking. The reciprocity within the social network facilitates learning: "there is an embroiderer, some knitters, and a good cook, so we can learn from each other”, „I share what I read with my friends, if they like it, they read mostly works by foreign authors, and I read those by Lithuanian writers - I would say we complement each other", „we can talk about everything that interests me or them, or the problems we face, and discuss the town news or political issues, or ask for advice“"

„Our generation are pushed aside“. Older adults perceive barriers to social engagement associated with ageing. Physical aspects of older age may be associated with reduced levels of socializing: ,people of your age stop visiting you - it's too cold to go out, or they have to heat their homes with wood burning stoves, or it's slippery outside and they have difficulty walking“. In addition, older adults may perceive the social aspects of old age as barriers to their social engagement continued in later life: ,at this age one feels as if being second-rate... when you used to be involved in a range of activities, it's like a step backward“. This belief may be embedded in shared experiences of the people of their cohort in relation to younger generations: „The cultural activities in the community are around the younger generation ... you don't feel like interfering into their activities .. there is change in traditions, everything is changing... community facilities are youth oriented, the culture centre has become the space for young people.. it feels as if the people of my age, our generation are pushed aside“. The barriers to social engagement continued in later life may also be embedded in older adults“ negative perceptions related to ageism: „I come to 
community events if invited, but nobody shows any interest... Nobody invites me. I wouldn't mind coming, but ...it might be because of my old age - a new generation is coming““

\section{Older adults adapt their learning to age-related changes and individual}

\section{circumstances}

The interview data showed that older adults' self-directed learning is strongly connected with their identification of themselves as ageing individuals and their response to the age-related changes. As related to learning in later life, there are two opposing aspects is interpretation of ageing: on the one hand, it may be perceived as a source of limited opportunities, but on the other hand, it may be an impetus for learning and a source of knowledge, skills and expertise.

"I am slower now than I used to be”. The participants were concerned about the older age related changes impacting their learning abilities or activities, including mental health issues, or reduced level of activity. The age changes may affect memory („I feel my memory is getting worse“), the concentration span (,[listening to online lectures] has become difficult, so I cannot listen to them for a longer time”), or visual abilities (,there are plenty of books now, but my eyesight has deteriorated with age“), cause health problems („I am a little afraid to go on longer journeys now`) or even result in decreased self-confidence (,I would like to learn some handicraft, but do not trust my abilities any more“). The research findings show that, contrary to common believes, health issues may not be a focus of older people learning („I doubt I can learn what to do about my health problems, therefore I must rely on specialists“"), or popular health education may be viewed critically (,All those modern ideas about healthy eating and lifestyle do not appeal to me, as they may change and different ideas may be developed tomorrow"), doubted („I don“t think there can be any learning about deterioration in old age”), considered confusing (,at first I started looking for literature on my disease, but it made me feel so bad about it all, so I gave up reading and went to see a famous phytotherapy professor..), or even opposed ("Sometimes it's better to know less about health issues, as it might make one anxious - we will live for as long as God allows us to").

„I have to learn so that they don't say: „you don't know, you are too old". Older adults may orientate their learning towards coping with ageing-caused limitations, thus viewing ageing processes as an incentive to engage in learning. Awareness of the stereotypical image of older age as a decline can encourage older adults to defy this image and put more effort into "keeping up with the rapid pace of life change“ or „go and see while you are able to". Alternatively, 
older age can be perceived positively as a circumstance which gives some advantage in terms of the learning experience and knowledge accumulated over years ("We have acquired enough knowledge ourselves through our lives to deal with our problems"), or which gives "more time for selfdevelopment”, "development of family relationships“, or „reflection on the meaning of life“. Older adults develop their own strategies to tackle the problems (,I am thinking a lot about improving my memory and mental activity“) or orientate their learning towards preparation for older age („One must try and do something so that those threats come slower"). Anticipation of older age may encourage the individual to design some long-term projects: „I've started thinking about what it will be like in old age, and started some preparation by improving things in the home related to heating and garden - so that running the home takes less energy“".

"I have been slightly depressed for some time". Taking advantage of learning opportunities is embedded in individual life circumstances (Spear, Mocker, 1984): some individual life circumstances may trigger learning or discourage an older person from engaging in activities. Some circumstances may encourage an older person to search for the ways of coping with psychological or existential problems: „My illness made me rethink many things in my life“. Looking after a sick family member for a long time or the death of a close person may make an older person to reflect on and alter one's understanding of the meaning and purpose of their activities, to rethink one's life roles and create the trajectories for the future: "Now my world has been shattered and I cannot orientate myself. There is confusion, tiredness, and I don't have the starting point. What am I doing? As I have become lone, I am trying to find out how I should proceed with my life, and find support".

\section{Discussion}

When exploring the learning experiences, it is important to take into consideration the nature of self-directed learning as an independent autodidactic process determined by the social context of learning. This study looks into the relationship between self-directed learning of older adults and their learning contexts as reported by older learners themselves. „The participants' meanings cannot be separated and discussed apart from the ecology in which the findings suggest they are richly located“" (Scott, 2004, p. 16). The learning ecologies which older adults create in their environments ,fit together contexts and situations, purpose, will and capability, relationships and resources in a dynamic process" (Jackson, 2013, p. 16). The analysis of the participants' 
learning experiences enabled us to identify those aspects of individual and social contexts which are significant to the realization of the participants' self-directed learning, and explore how participants utilized the learning opportunities provided by social environments in their self-directed learning.

Our data suggests that older adults' generativity has significant implications for better understanding of later life learning. The role of generativity in later life has been promoted in older adult research in the last decade (Villar, 2012). As linked to later life learning, active and productive functioning of older adults requires certain competences, which are based on acquisition of new knowledge and development of skills relevant to engagement in the new type of activity. As "concern in establishing and guiding the next generation"' (Erikson, 1963, p. 276), generativity is also linked to older individuals' contribution to their environments. The wide range of experiences and skills accumulated over the years are seen as "resources which may serve to invigorate daily life in neighbourhoods" (Buffel et. al, 2012, p. 22). Our research points to the generativity-oriented nature of older adults' self-directed learning behaviour. Older adults engage in learning in generativity-based environments motivated by the desire to be „,needed“ and able to contribute to their social environments.

The participants demonstrated their concern with contributing to the community by engaging in activities promoting the history and culture of their neighbourhood. This provides a rich learning space for their self-directed learning and also potential for other community members to be involved in the learning process. „History, tradition and culture are considered potential means to facilitate informal learning processes in a particular neighbourhood" - "having a strong sense of history, older people can pass down cultural traditions to younger generation” (Buffel et al., 2012, p. 22). Some recent research also indicated that productive activities after retirement can provide considerable learning stimuli (Golding, 2011) and taking on responsibility in different fields of life is highly conducive for learning (Schmidt-Hertha, 2013).

The research findings indicate, that the generativity-oriented environments may be challenging and demanding for older adults in terms of competences required for performance of productive activity. Friebe, Schmidt-Hertha (2012) also argue that civic engagement or caring about others can initiate learning processes if those activities are challenging and demand new competency. Although some of the learning which occurs in productive environment may be incidental, our research demonstrates, that through engagement in productive activity older adults develop their learning patterns which allow acquiring the knowledge and skills needed for 
performing the task. This has been indicated by some other recent research, when older adults reported on "forms of self-directed learning aimed at solving new tasks or doing what they do in a more professional manner" (Schmidt-Hertha, 2013, p.94). In addition, productive activity allows the older adult to maintain self-sufficiency and be in control of their lives (Eisen, 1998).

In much of gerontological literature leisure is considered a context in which the retired individual can construct new activities and opportunities for personal growth through active and dynamic participation (Luppi, 2009, p. 248). Research shows that a considerable proportion of the learning activities among older adults are involving self-study and the pursuit of hobbies and interests (Withnall, 2010). Our research suggests that older adults engage in learning in interestbased environments to maintain their identities, or to find new ways of self-actualization. The participants purposefully chose resources within their environments, developing learning patterns adapted to the age-related constraints.

When analysing learning in interest-based activities, there is the question of the extent to which older adults are conscious of their learning, which is not the primary objective of the activity, but rather a bi-product of the process of trying to accomplish something (Eraut, 2004). Our evidence suggests that the learning may be consciously realized by the older adult, as the learning element was explicit in the interest-related activities of the participants, and they were able to clearly articulate what value those activities had for them in terms of learning. Older adults reflect on the worthwhileness of the activities and weigh them against the criteria of meaning and purpose. This may be associated with the limited resources of time and efforts of an ageing individual. Scott's (2004) findings suggest that ,individuals give time and priority to pursuits that are congruous with their life trends and interests“" (p. 17). Moreover, the participants" accounts of their engagement in interest-based activities demonstrated the goal-oriented nature of the activity. The commitment to the goal was manifested in the complexity of the activity and the efforts the older people put in achieving the goals. As Roberson's (2004) study of rural older people in the USA suggested, the goal-directed nature of learning takes an older individual „beyond fascinating hobbies and alluring pastimes to specific learning" (p. 210). Our study demonstrated that older adults put efforts to acquire the knowledge and skills needed to improve their performance in the interest-oriented activity.

The learning elements may also be implicit in the older adults'engagement in the activities, when the interest-oriented activity provides a natural environment for learning, and the 
person develops a learning pattern without consciously realizing it, but just „listening to one“s inner guidance“. However, such ,incidental learning is highly dependent on learning opportunities presenting themselves in everyday life and is embedded in challenging tasks (Schmidt-Hertha, 2013). As argued by Schmidt-Hertha (2013), internal impulses for older adults to learn are linked to individual dispositions to follow their personal interests or worries about losing cognitive skills (Schmidt-Hertha, 2013, p. 98). Our research indicates that older adults may pursue excellence in the activity or challenge themselves with new and more complex tasks. Moreover, our research shows that older adult engagement in interest-related activities provides a stimulating context for their selfdirected learning. Similar to research on older adults ${ }^{\star}$ areas of interest, reported by Tam and Boulton-Lewis, our study suggests that older people are interested in matters relevant and meaningful to their lives, related to leisure and personal development, and they engage in activities to keep their minds active (Boulton-Lewis et al., 2016; Tam \& Chui, 2016). However, engagement in activity may be impacted by the resources available in the older person's physical and social environment. As pointed out by Freibe and Schmidt-Hertha (2012), living space and environment become increasingly significant at an older age due to the decreasing mobility and the resulting increasing importance of accessibility of service structures. Our evidence shows that older adults purposefully identify and selectively take advantage of the resources in their community environment. The participants' selective attitude towards community offered activities was influenced by the individual factors, including the person's needs and interests, which may confirm that adults have very little inclination to really learn something they do not perceive as meaningful for their own life goals (Illeris, 2003). Moreover, taking advantage of the community-provided opportunities was embedded in the individual life circumstances (Spear \& Mocker, 1984), triggering or hindering learning.

Similar to other recent research studies on learning in later life (Tam \& Chui, 2016), the findings of the present study suggest that older adults associate their learning with expressive needs by relating it to their personal development and development of social relationships. The role of the social environment in older people's lives is defined as "a dynamic, multi-dimensional, historically and spatially contextualized process that both shapes and is shaped by the experiences and practices of older people" (Buffel et al., 2012, p. 14). There is a large body of research about adult learning as an active process constructed through social interaction (Merriam and Clark 2006; Taylor and Lamaroux 2008). Learning in later life is also viewed as related to the social 
environment and the social network (Findsen \& Formosa, 2011, Schmidt-Hertha, 2013), as a social construct created in and subject to change in social interaction (Mezirow, 1991). Our study shows that older adults construct their learning using the opportunities provided in their immediate social environments.

Well-established social connections may facilitate self-directed learning by providing secure and stimulating learning environment. In addition, „the richness of the retired person's social interactions increase the possibilities of more productive learning through retirement" (Hodkinson et al., 2008, p. 182). Neikrug et al. (1995) study indicated that older adults continue social contacts from their previous lives whenever possible or develop new associations to meet their needs. Our study suggests that older adults' maintain "life-long" relationships and social contacts from their pre-retirement environment or their immediate environment. However, our data provided no evidence pointing to the participants being inclined to establish new friendships. Other people including friends, neighbours, experts are usually involved in self-directed learning projects at some stage (Lamdin, 1997, p. 120), as cited in Roberson (2005). Our study demonstrates that social interaction becomes a resource for gaining knowledge or skills: older adults rely on knowledgeable people in their immediate social environments including family, friends, neighbours or community professionals.

Social interaction and maintenance of local social networks may be viewed as conditions for learning and sources for learning. These findings are similar to the results of some other recent studies of later life learning through social interaction which indicated that older people use information sources in the social environment to solve particular problems (Carragher, Golding, 2015; Schmidt-Hertha, 2013). Moreover, our study indicates that learning through social interaction may be preferred to getting knowledge through other modes of learning. The significance of a wider social network is argued by researchers indicating that although family is central to many older people, "learning is often related to activities and interactions with friends, neighbours or members of associations they are engaged in (Schmidt-Hertha, 2013, p. 95). Our study also demonstrated that social interaction and social networks serve as an incentive to learning when older people are directly encouraged to learning and supported by people in their immediate environment.

The participants reported mutual construction of knowledge in their social networks, as an informal give-and-take (Pfahl, 2011). Our study points to a connection between an older person's engagement in learning and establishing oneself and maintaining one's status in the social 
environment. The barriers to social engagement continued in later life are embedded in older adults ${ }^{6}$ negative perceptions of social constraint in terms of ageism. Although the participants reported negative perceptions of the diminishing role of older people in the community life as a shared experience (Biesta et. al., 2010), they showed resistance to internalize the ageist stereotypes by emphasizing their pursuit of generativity and self-development.

The participants made their learning related decisions and constructed their learning opportunities in their learning contexts with consideration of the individual contexts - aging-related and individual circumstances. The interview data showed that older adults' self directed learning is strongly connected with their identification of themselves as ageing individuals and their response to the aging-related changes. As pointed out by Roberson (2005), ,the self-image of older adults is often in repair because of obvious changes in the physical body and because he/she cannot meet previous goals" (p. 8). Age is a predictor of educational behaviour like situational factors, circumstances, social or vocational background (Friebe \& Schmidt-Hertha, 2012, p. 68). As related to learning in later life, ageing may be perceived as a source of limited opportunities. The key finding of Roberson's (2004) study on older rural adults was the importance of self-directed learning in the lives of older adults in making necessary adjustments in later life. Age-related change can motivate older adults to learn "what is necessary to continue to live a full and active life" (Roberson, 2005). Although the respondents in our study did not explicitly associate their learning activities with adjustment to ageing, the research findings indicate that the participants related their learning with continued productive activity and personal development. Age-related changes were generally viewed as some constraints to their continued engagement in learning, and the participants responded by adapting the patterns of learning behaviour, i.e. adjusting their learning strategies to the new circumstances.

There is a large body of research on health-related learning and older adults focusing on the benefits of health education for older adults as this segment of population is associated with facing the greatest health risk (Valente, 2005). Valente (2005) in her study on the role of selfdirected learning in older adults' health care, argues that engagement in self-directed learning helps older adults "to take charge and control their specific health issues with a new sense of awareness and sensitivity about their health" and "they often choose to examine a variety of educational resources to determine, evaluate and understand treatment options" (p. 419). However, our data points to a different attitude of the participants indicating that health issues may not be a focus of 
older people learning. Older adults may critically view popular health education, or even oppose learning about health issues.

Ageing may be perceived as an incentive for learning. Our study shows that it is the awareness of the stereotypical image of older age as a decline that may encourage older adults to defy this image and put more effort into their learning to "keep up with the rapid pace of life change“. Our study demonstrates that aging may also be perceived as a source of knowledge, skills and expertise. Neikrug (1998) argues for the value of gerontological knowledge for elders: “increased knowledge on aging can provide elder persons with anticipatory socialization" (p. 287). The participants reported their interest in learning about age-related issues and their efforts to find ways for coping with age-related conditions. The participants in our study developed their own strategies to tackle the problems or orientate their learning towards preparation for older age. Certain life circumstances may become significant to learning experiences, triggering or hindering learning (Spear \& Mocker, 1984). There is a large body of research showing that significant loss may cause emotional instability to an older person, which can contribute to diminished confidence, or depression (Roberson, 2005, p. 8). Most of the participants, who had experienced long periods of looking after sick family members or deaths of their spouses, reported the feelings of depression. However, our study demonstrates that older adults develop strength and resilience when faced with unfortunate life circumstances, which encourages them to create their own pathways for coping with the situations. It may be an indication of an advantage of age in terms of the learning experience and knowledge accumulated over years, which facilitates older adults learning to perform the new roles and create future trajectories.

\section{Conclusions}

The purpose of this research was to investigate how self-directed later life learning is utilized and interpreted by older adults in their particular environments. The findings of the study highlight the importance of the learning contexts to the realization of self-directed learning in later life. Three conclusions regarding the relationship between the self-directed learning of older adults and their particular contexts can be made based on the results of the study: i) older adults' engagement in generativity-based activities, interest-based activities and social networks is the context of self-directed learning in later life; ii) these contexts support older adults' self-directed 
learning by providing learning impetus, opportunities and resources; iii) realization of self-directed learning is influenced by ageing-related changes and individual circumstances of older adults.

Further exploration of the links between the self-directed learning of older adults and the contexts would benefit from extension of research to larger samples of older people in a larger variety of learning environments, which would allow for capturing the complexity of the dynamics between the older adult engagement in self-directed learning in a number of learning environments and the individual circumstances affecting the learning. This study may have practical significance to adult education providers' practice on how older adult learning could be facilitated by identifying learning needs and opportunities as linked to their environments.

\section{References}

1. Berger, P., Luckmann, T. (1999). Socialinis tikrovès konstravimas. Vilnius: Pradai.

2. Biesta, G., Field, J., \& Tedder, M. (2010). A time for learning: representations of time and the temporal dimensions of learning through the lifecourse. Zeitschrift für Pädagogik, 56(3), 317-327.

3. Boulton-Lewis, G. M., Buys, L., \& Lovie-Kitchin, J. (2006). Learning and Active Aging, Educational Gerontology, 32(4), 271-282.

4. Boulton-Lewis, G. M., Tam, M., Buys L., \& Chui, E.W. (2016). Hong Kong and Australian seniors: Views of aging and learning. Educational Gerontology, 42(11), 758-770.

5. Braun, V., \& Clarke, V. (2006). Using thematic analysis in psychology. Qualitative Research in Psychology, 3(2), 77-101.

6. Braun, V., \& Clarke, V. (2014). Guest Editorial: What can 'thematic analysis offer health and well-being researchers? International Journal of Qualitative Studies on Health and Well-being, 9, 26152. Available at: https://www.ncbi.nlm.nih.gov/pmc/articles/PMC4201665/.

7. Buffel, T., Verté, D., De Donder, L., De Witte, N., Dury, S., Vanwing, T., \& Bolsenbroek, A. (2012). Theorising the relationship between older people and their immediate social living environment. International Journal of Lifelong Education, 31(1),13-32.

8. Candy, P. C. (1991). Self-direction for lifelong learning: a comprehensive guide to theory and practice. San Francisco: Jossey-Bass.

9. Carragher, L.. \& Golding, B. (2015). Older Men as Learners: Irish Men's Sheds as an Intervention. Adult Education Quarterly, 65(2), 152-168.

10. Cummins, S. A. (2010). Feedback 2.0: An investigation into using sharable feedback tags as programming Feedback. Durham University. Available at: http://etheses.dur.ac.uk/400. 
11. Eisen, M. (1998). Current practice and innovative programs in older adult learning. In. J.C. Fisher and M.A. Wolf (Eds.), Using learning to meet the challenges of older adulthood (pp. 41-55). New Directions for Adult and Continuing Education, No.77. San Francisco: Jossey-Bass.

12. Eraut, M. (2004). Informal learning in the workplace. Studies in Continuing Education, 26(2), 247-273

13. Erikson, E. H. (1963). Childhood and Society. New York: Norton.

14. Findsen, B., \& Formosa, M. (2011). Lifelong learning in later life: A handbook on older adult learning. Rotterdam, The Netherlands: Sense Publishers.

15. Friebe, J., \& Schmidt Hertha, B. (2012). Educational Activities and Barriers to Education for Elderly People in the Community. Intergenerational solidarity and Older Adults'Education in Community. Proceedings of the third conference of the ESREA Network on Education and Learning of Older Adults. 2012 September 1921. Ljubljana: University of Ljubljana.

16. Glendenning, F. (1992). Educational Gerontology and Gerogogy: a critical perspective. Gerontology \& Geriatrics Education, 13(1/2), 5-22.

17. Golding, B. G. (2011). Social, Local, and Situated: Recent findings about the effectiveness of older men's informal learning in community contexts. Adult Education Quarterly, 61(2), 103-120.

18. Hiemstra, R., \& Brockett, R.G. (2012). Reframing the Meaning of Self-Directed Learning: An Updated Model. Adult Education Research Conference. Available at: http://newprairiepress.org/aerc/2012/papers/22.

19. Hodkinson, P., Ford, G., Hodkinson, H., \& Hawthorn, R. (2008). Retirement as a learning process. Educational Gerontology, 34, 167-184.

20. Howe, K.R., \& Moses, M.S. (1999). Ethics in Educational Research. Review of Research in Education, 24, 21-59.

21. Illeris, K. (2003). Towards a contemporary and comprehensive theory of learning. International Journal of Lifelong Education, 22(4), 396-406.

22. Jackson, N. J. (2013). Personal Learning Ecology Narratives. In N. J. Jackson and G. B. Cooper (Eds.). Lifewide Learning, Education and Personal Development. E-book. Available at: http://www.lifewideebook.co.uk/research.html.

23. Jarvis, P. (2012). Learning from Everyday Life. HSSRP, 1(1), 1-20. Available at: http://hssrp.uaic.ro/continut/1.pdf.

24. Kasworm, C. (2011). New Perspectives on Post-Formal Cognitive Development and Self-Directed Learning. International Journal of Self-Directed Learning, 8(1), 18-28.

25. Kvale, S., \& Brinkmann, S. (2009). Interviews: Learning the craft of qualitative research interviewing. Thousand Oaks, CA: Sage Publications.

26. Lincoln, Y. S., \& Guba, E. G. (1985). Naturalistic inquiry. Beverly Hills, CA: Sage. 
10.1515/arhss-2017-0002 Applied Research in Health and Social Sciences: Interface and

Interaction, Vol. 14, No. 1, 2017

27. Luppi, E. (2009) Education in old age: An exploratory study. International Journal of Lifelong Education, 28(2), 241-276.

28. Merriam, S. B., \& Bierema, L. L. (2014). Adult learning: Linking theory and practice. San Francisco, CA: Jossey-Bass.

29. Merriam, S. B., \& Caffarella, R. S. (1999). Learning in Adulthood: A Comprehensive Guide. San Francisco: Jossey Bass.

30. Merriam, S. B., \& Clark, M. C. (2006). Learning and development: The connection in adulthood. In C. Hoare (Ed.). Handbook of adult development and learning (pp. 27-51). London: Oxford University Press.

31. Merriam, S.B., Caffarella, R.S., \& Baumgartner, L.M. (2007). Learning in adulthood: A comprehensive guide. (3rd Ed.). San Francisco: Jossey-Bass.

32. Mezirow, J. (1991). Transformative Dimensions Of Adult Learning. San Francisco: Jossey-Bass.

33. Neikrug, M. S. (1998). The Value of Gerontological Knowledge for Elders: A Study of the Relationship between knowledge on Aging and Worry about the Future. Educational Gerontology, 24, 287-296.

34. Neikrug, S., Ronen, M., Glanz, D., Alon, T., Kanner, S., Kaplan, A. et al. (1995). A special case of the very old: Lifelong learners. Educational Gerontology, 21, 345-355.

35. Owen, T. R. (2002). Self-directed Learning in Adulthood: A Literature Review. Available at: http://www.eric.ed.gov/contentdelivery/servlet/ERICServlet?accno=ED461050.

36. Patton, M. Q. (1990). Qualitative evaluation and research methods (2nd Ed.). Newbury Park, CA: Sage.

37. Pfahl, N. L. (2011) Using Narrative Inquiry and Analysis of Life Stories to Advance Elder Learning. In G. Boulton-Lewis \& M. Tam (Eds.). Active aging, active learning: issues and challenges. (pp.67-87). New York, NY: Springer.

38. Roberson, D. N. (2004). The nature of self-directed learning in older rural adults. Ageing International, 29(2), 199-218.

39. Roberson, D.N. (2005). The Potential of Self-Directed Learning. Activities, Adaptation \& Aging, 29:3, 1-20.

40. Schmidt-Hertha, B. (2013). Informal learning of older adults: Motives and opportunities in everyday life. Proceedings of $4^{\text {th }}$ International ESREA Conference. (pp. 77-88). Learning Opportunities for older adults: forms, providers and policies. Vilnius: Mykolo Romerio Universitetas.

41. Schugurensky, D. (2000). The forms of informal learning: towards a conceptualization of the field. WALL Working Paper $19 . \quad$ Available at: https://tspace.library.utoronto.ca/bitstream/1807/2733/2/19formsofinformal.pdf.

42. Scott, K. W. (2004). Congruous autonomy: the 'pull' of personal commitment to extraordinary involvement in a pursuit. MPAEA Journal of Adult Education, 33(1), 7-18.

43. Spear, G. E., \& Mocker, D. W. (1984). The Organizing Circumstance: Environmental Determinants in Selfdirected Learning. Adult Education Quarterly, 35(1), 1-10. 
10.1515/arhss-2017-0002 Applied Research in Health and Social Sciences: Interface and

Interaction, Vol. 14, No. 1, 2017

44. Tam, M., \& Chui, E. (2016). Ageing and learning: What do they mean to elders themselves? Studies in Continuing Education, 38:2.

45. Tam, M. (2013). A Model of Active Ageing Through Elder Learning: The Elder Academy Network in Hong Kong. Educational Gerontology, 39, 250-258.

46. Taylor, K., \& Lamaroux, A. (2008). Teaching with the brain in mind. In S. B. Merriam (Ed.), Third update on adult learning theory. (pp. 49-59). San Francisco: Jossey-Bass.

47. Tusting, K., \& Barton, D. (2006). Models of adult learning. Leicester, UK: National Institute of Adult and Continuing Education (NIACE).

48. Valente, J. S. (2005). The Role of Self-Directed Learning in Older Adults' Health Care. UNpublished doctoral dissertation. Athens: University of Georgia.

49. Villar, F. (2012). Successful ageing and development: the contribution of generativity in older age. Ageing and Society, 32, 1087-1105.

50. Withnall, A. (2006). Exploring influences on later life learning. International Journal of Lifelong Education, 25(1), 29-49.

51. Withnall, A. (2010). Improving learning in later life. New York: Routledge. 